\title{
"PEER OBSERVATION": A OBSERVAÇÃO ENTRE PARES COMO FORMA DE (RE)SIGNIFICAÇÃO DO PROCESSO DE AVALIAÇÃO NA GESTÃO DEMOCRÁTICA E PARTICIPATIVA.
}

\author{
Mariana Araujo Zaneti Gonçalves, Maria Eliza Nigro Jorge (orientadora) \\ Universidade do Oeste Paulista (UNOESTE), Curso de Pós-Graduação Latu Sensu em Gestão Escolar: Administração e \\ Supervisão sob a orientação da professora Maria Eliza Nigro Jorge. E-mail: marianazaneti@gmail.com
}

\section{RESUMO}

O objetivo deste artigo é mostrar uma alternativa para a questão da avaliação em um contexto de gestão democrática e participativa através da observação entre pares. Tal exercício avaliativo afasta-se um pouco do modelo centralizado e punitivo da avaliação, propiciando a troca de ideias e experiências entre colaboradores do mesmo nível hierárquico no ambiente escolar. Em tal modelo a equipe gestora trabalha na mediação do processo avaliativo, preparando os colaboradores para as sessões de observação e de feedback e também ajudando na escolha de aspectos específicos a serem observados. Neste artigo abordamos especificamente o viés pedagógico, tomando como base a questão da observação de aulas da equipe docente sob mediação do coordenador/orientador pedagógico e procurando mostrar as vantagens desse tipo de avaliação no processo de formação continuada e de aperfeiçoamento da equipe docente. Palavras-chave: Gestão Escolar Participativa. Observação de pares. Avaliação.

\section{THE PEER OBSERVATION AS A FORM OF (RE) MEANING OF THE EVALUATION PROCESS IN DEMOCRATIC AND PARTICIPATIVE MANAGEMENT.}

\begin{abstract}
The objective of this article is to show an alternative to the question of evaluation in a context of democratic and participative management through peer observation. This evaluation exercise goes in an opposite direction from the centralized and punitive model of evaluation, allowing the exchange of ideas and experiences among employees of the same hierarchical level in the school environment. In this evaluative model the management team works on the mediation of the evaluation process, preparing the employees for the observation and feedback sessions and also helping to choose specific aspects to be observed. In this article, we focus specifically on the pedagogical bias, based on the observation of the teaching staff 's classes under the guidance of the pedagogical coordinator and trying to show the advantages of this type of evaluation in the process of continuous training and improvement of the teaching staff.
\end{abstract}

Keywords: Participative School Management. Peer Observation. Evaluation. 


\section{INTRODUÇÃO}

Quando falamos em Avaliação Institucional no âmbito empresarial pensamos mais na satisfação dos clientes, no cumprimento de prazos e metas e em questões mais quantitativas.

Pensando em temos educacionais, temos que primeiramente analisar as especificidades da "empresa" escola e dos "serviços" por ela prestados. Como "medir" a eficácia da Instituição Escolar? Quais são os membros participantes dessa avaliação? Quem avalia? Quem é avaliado?

Pensando em um contexto de gestão democrática e participativa, lembramos que o processo de avaliação, assim como todos os outros processos, não deve ser autoritário e centralizado. Ainda hoje, quando se discute avaliação e planejamento, muitas pessoas pensam na figura centralizada do gestor, que define como devem ser as ações e que faz uma avaliação rígida e pouco aberta dos resultados. Uma gestão democrática, no entanto, caminha na direção oposta.

A participação de todos os membros da comunidade escolar (gestores, professores, pais, alunos, comunidade...) no processo de tomada de decisão e na definição das metas e planos de ação é essencial para o sucesso do processo. Levar em consideração as especificidades de cada comunidade, suas necessidades, pontos fortes e fracos também é essencial.

A avaliação vem no sentido de verificar se as atividades planejadas foram realizadas de forma satisfatória, ou seja, em que medida o que foi planejado foi colocado em ação. Vale lembrar que tal processo deve ser coerente com a instituição escolar e com o seu contexto, ou seja, é preciso considerar a escola como instituição que desenvolve uma cultura própria.

E nesse modelo de gestão democrática e participativa, qual o papel da coordenação e direção? Qual seria a dimensão do trabalho dos gestores? Aos gestores cabe conduzir o processo de avaliação atuando como facilitadores e mediadores, motivando toda a equipe e levando sempre em consideração o contexto, necessidades e cultura da instituição educacional para garantir o êxito do processo.

Nesse sentido, a observação entre pares vem para desconstruir a ideia de avaliação como algo "punitivo", com foco nos erros e também para efetivar um modelo avaliativo pautado na troca de experiências, na reflexão acerca das práticas e na construção coletiva de novos saberes.

\section{A Gestão Escolar e suas especificidades}

Se consultarmos no dicionário, vemos a definição de "gestão" como administração, como a ação de gerir, de administrar, de governar ou de dirigir negócios públicos ou particulares. Trata-se da gerência, da função ou exercício da pessoa responsável pela administração.

Quando falamos em gestão escolar, no entanto, temos que levar em consideração as especificidades do "negócio" gerido. A escola, como toda empresa, precisa de uma equipe gestora que organize a parte funcional e financeira, mas como o "produto" da escola é algo subjetivo e delicado, o trabalho do gestor escolar e sua organização segue também algumas características bem particulares.

Partindo de uma visão atual, de gestão democrática e participativa, temos como principal atividade do gestor, na organização e norteamento do seu trabalho, a busca de formas de engajamento de todos os membros da comunidade escolar, a criação do interesse de todos pelos objetivos daquela instituição, a contextualização daquele espaço na comunidade a qual pertence e o entendimento das necessidades particulares da sua "clientela".

Nesse sentido, Chiavenato (2010, p. 14) ainda cita que:

No seu trabalho, cada administrador - seja ele um diretor, gerente, chefe ou supervisor desempenha as quatro funções administrativas que constituem o processo administrativo, a saber: planejar, organizar, dirigir e controlar. A Gestão de Pessoas procura ajudar o administrador a desempenhar todas essas funções porque ele não realiza seu trabalho sozinho, mas através das pessoas que formam sua equipe. 
Quando pensamos em montar ou gerir uma escola, estamos pensando em colocar em prática uma determinada visão social e política, uma ideologia, estamos lidando com a formação de pessoas, com um meio de transformação e formação social.

Assim, ao gestor educacional fica a tarefa de fugir da visão meramente capitalista empresarial e enxergar a instituição que organiza com um olhar social, formativo e crítico. Gerir os recursos e organizar o trabalho, mas pensando sempre no viés de transformação social que essa organização possibilitará.

O desafio atual da gestão escolar é quebrar as barreiras da visão autoritária e hierarquizada das instituições educacionais e voltar os olhos para um modelo de gestão aberta e participativa. 0 desafio é convencer as pessoas a serem ativas nesse tipo de gestão, trazer a comunidade para dentro da escola, despertar em todos os funcionários o desejo de pertencer aquilo, de fazer parte não só dentro de suas funções, mas trabalhando na construção e organização, como vozes complementares da equipe gestora.

Sabemos que o gestor precisa controlar, estipular os papéis e funções, gerir os recursos e definir os caminhos a serem seguidos, mas atualmente essa gestão pode se dar mais na forma de mediação e orientação do que na centralização de todo o trabalho e tal modelo serve também e principalmente para a questão da avaliação.

\section{(Pre)Conceitos acerca da atividade de avaliação}

Ainda hoje o conceito de avaliação está muito associado à ideia de crítica, a algo que assusta e que serve apenas para apontar defeitos ou para cumprir uma atividade meramente burocrática, quando na verdade é uma importante ferramenta para o aprimoramento, para averiguação dos pontos positivos e negativos de determinada forma de ação e para o desenvolvimento dos planos de ação.

Em relação à educação, essa noção "quantitativa" da avaliação causa certo desconforto devido ao teor subjetivo do processo de ensino/aprendizagem mas, justamente pelo fato da escola ser uma "empresa" com uma "mercadoria" tão singular quanto à educação, essa "medida" é bastante importante para (re)definição dos caminhos a seguir.

Cada vez mais faz-se necessário um modelo de avaliação global, crítico, que inclua toda a comunidade escolar, que tenha a participação dos professores e dos gestores em um processo de reflexão de toda a prática escolar (práticas pedagógicas, políticas, administrativas, sociais, programas, infraestrutura...).

Deve-se ainda levar em conta que a avaliação é um processo contínuo e não pontual, que deve ser constantemente analisado e verificado em sua eficácia e efetividade.

"A formação dos professores seria um processo contínuo e permanente de desenvolvimento", como afirma Tardif (apud OLIVEIRA; SILVA, 2008, p. 45).

Pensando nisso, a avaliação deve ter como objetivo oferecer aos docentes um instrumento de acompanhamento pedagógico visando ao processo de desenvolvimento institucional e ao estabelecimento de novas práticas e didáticas através da troca de experiência e não de uma imposição estanque e hierarquizada.

\section{"Peer Observation": (re)significando o processo de Avaliação Docente}

Pensando em um modelo de gestão democrática e participativa, faz-se necessário uma ressignificação do processo de avaliação, quebrando a ideia de algo estanque, centralizado e unilateral.

Nesse contexto, a observação entre pares, isto é, entre pessoas com a mesma função dentro da hierarquia escolar, pode ser uma ferramenta eficaz para uma mudança no paradigma avaliativo historicamente construído. Mais especificamente pode-se dizer que "A observação em 
parceria ou em pares é uma dinâmica de trabalho colaborativo (GOSLING, 2009) em que o parceiro ou par é um colega cuja circunstância é equivalente à nossa."

As observações entre pares servem como veículos para o crescimento profissional e podem ter múltiplos benefícios - para os professores, para as lideranças e para a escola, uma vez que a equipe se sente menos pressionada e mais envolvida no processo avaliativo em si.

Ao gestor caberia nesse processo a mediação, a orientação da equipe no que tange ao verdadeiro sentido das observações de aula e feedback, desmitificando a ideia de algo punitivo e impositivo e voltando os olhares para a troca de experiências que contribui para as melhorias, que se constrói na reflexão, no debate e não só no elencar dos erros;

Caberia ainda a ele traçar os planos de ação com toda a equipe pedagógica e utilizar as reflexões e debates como uma forma de ressignificação do trabalho e de formação continuada.

Vale ressaltar aqui que a observação entre pares é um processo coletivo, ancorado na reflexão conjunta, na análise e discussão de situações observáveis e com ênfase da no diálogo e na reflexão.

\section{METODOLOGIA}

O primeiro passo de um processo avaliativo pautado na observação entre pares seria o trabalho com a sensibilização e preparação da equipe para o projeto de observação de pares.

Primeiramente, fala-se um pouco sobre a importância da observação de colegas e da troca de experiências, didáticas e metodologia para o aperfeiçoamento do trabalho pedagógico.

O gestor (coordenador/orientador pedagógico) fala então sobre a sensibilidade necessária no processo de feedback e nos objetivos da observação de aula, que está longe de visar o elencar de erros, mas gerar reflexão e debate acerca das práticas.

O trabalho de sensibilização com o colocar-se no lugar do outro aqui é fundamental para que o feedback não se torne um aglomerado de críticas e promova mesmo uma troca construtiva e não um clima pesado de cobranças e competitividade.

Após a sensibilização e preparação motivacional da equipe para o projeto, é feita então a divisão dos pares e o calendário das observações.

O professor cuja aula será observada manda ao professor observador o plano de aula uma semana antes. O professor observador faz as suas observações acerca do planejamento e, se tiver alguma dúvida, conversa com o professor observado.

Após a observação da aula, repete-se o processo, mas dessa vez o professor observado torna-se o observador.

A separação dos pares deve ser feita pensando-se em uma união de professores com didáticas diferentes ou que não tem tanto contato, para que a troca de experiência seja enriquecedora.

Então, após a preparação e entrega dos planos de aula, o professor observa a aula e faz anotações de acordo com aspectos a serem analisados (a coordenação ajuda na elaboração desse documento). Ao final da observação, o professor observador tem uma breve conversa com o professor observado, na qual expõe suas impressões gerais.

Os professores então trocam de posição: o que foi observado torna-se observador, e repete-se o processo.

Após atuarem como observados e observadores, os professores agendam então um horário para trocarem suas impressões acerca das aulas observadas.

Tal feedback pode contar com a supervisão ou coordenação para a especificação de planos de ação no sentido de formação continuada.

O ideal é que a sessão de feedback aconteça após uma palestra ou atividade motivacional, em um ambiente descontraído, para que todos se sintam mais confortáveis e para que a sessão funcione mesmo como uma troca de ideias. 
Após a primeira observação, a dupla de professores se reúne com a equipe gestora para estabelecer planos de ação e metas e para dizer em que a observação contribuiu para as práticas em sala de aula.

Outras observações são marcadas, com os mesmos pares ou pares diferentes, ao longo do período letivo.

Ao término do processo, dependendo dos problemas apontados ou das ideias que surgirem, a equipe gestora prepara palestras e indica leituras para contribuir com a formação continuada da equipe docente.

\section{RESULTADOS ESPERADOS}

Como resultados esperados para a avaliação entre pares, podemos dizer que tal modelo proporciona aos docentes a possibilidade de apenas assistir e refletir - ser de novo estudante (não o sendo), o que pode também favorecer a compreensão de como os alunos se sentem nas aulas.

Há ainda a possibilidade de colocar em perspectiva as nossas próprias convicções sobre o ensino. Enquanto profissionais, será que chegamos a tal ponto de perfeição que não podemos ser surpreendidos por uma nova forma de estar em sala de aula?

Mais importante, cria-se no modelo de interação entre pares a noção de suporte mútuo e a construção da identidade de grupo. Dessa forma, o trabalho da equipe gestora é dividido, pois os próprios docentes acabam sendo membros ativos de sua formação continuada e de seus colegas, através de suas ideias, experiências e reflexões.

Deve-se pensar ainda nos riscos derivados do pré-conceito de alguns docentes sobre o que seria um "bom ensinar" ou ainda nas interpretações diferentes, dependendo de como olhamos, do quanto olhamos e do que conhecemos sobre o contexto da aula observada.

Nesse viés, professores mais experientes ou menos abertos a críticas construtivas podem sentir-se desmotivados ou afrontados com os apontamentos dos colegas, bem como professores menos experientes podem sentir-se inseguros em falar sobre aspectos a serem melhorados.

Para controlar tais riscos, cabe a coordenação/orientação pedagógica trabalhar na sensibilização e na preparação da equipe. É o gestor o principal responsável por criar um ambiente propício para essa troca de ideias colaborativa, ouvindo e amenizando as angústias de sua equipe em relação a visão enraizada de avaliação como algo negativo.

A preparação para o feedback também é essencial, uma vez que deve ser evitado, nesse contexto, o "feedback corretivo" (aquele que levanta críticas e faz objeções) e valorizado o "feedback estimulador", que funciona como incentivo, reconhecendo pontos positivos no trabalho que a pessoa realizou ou na tarefa que se empenhou a cumprir.

\section{CONCLUSÃO}

Pensando em um modelo de gestão democrática e participativa, o modelo avaliativo pautado na observação de pares consegue atingir o objetivo de desmistificar a noção de avaliação como algo punitivo e centralizado e a configurar a tal processo como uma troca de ideias e reflexões acerca das práticas.

Trata-se de enxergar o processo de ensino e aprendizagem como algo contínuo e construído coletivamente, com espaço para reflexão, preparação e auto avaliação, e com o objetivo de promover melhorias e atingir ou até mesmo traçar os objetivos da Instituição Escolar.

Cada aula observada, seja na condição de observado ou de observador é uma oportunidade de aprendizagem, ou seja, é um processo formativo.

O trabalho do gestor escolar não precisa (e nem deve) ser solitário. O gestor deve agir como um mediador, alguém que fomenta as discussões, que direciona, mas está longe de ser o protagonista no processo, seja ele de planejamento ou de avaliação. 
A participação ativa dos docentes no processo avaliativo e de formação é de extrema importância para o envolvimento desses profissionais com a escola, com suas metas, com seu projeto político e pedagógico, com seu contexto e comunidade.

Quando falamos em formação, estamos falando da reflexão diária acerca das práticas, da discussão de teorias atuais, da avaliação institucional, de grupos de estudo, de observações e feedback.

Uma equipe preparada e que constantemente avalia as próprias práticas é chave para uma gestão escolar funcional e efetiva. A reflexão crítica acerca das práticas é essencial para elaboração e alcance das metas e para a evolução da comunidade escolar como um todo.

Assim, podemos concluir que o aperfeiçoamento e a formação não se dá na transmissão do conhecimento, mas na sua construção, na interação e na troca de experiências, no reconhecimento dos pares como colaboradores e não como concorrentes, na ajuda mútua e na formação de uma Comunidade Escolar, na qual cada membro é parte fundamental para o sucesso do processo de ensino/aprendizagem.

\section{REFERÊNCIAS}

CHIAVENATO, I. Gestão de Pessoas. 3. ed. Rio de Janeiro: Elsevier, 2010.

GOSLING, D. Guidelines for peer observation of learning and teaching: for Escalate Regional Networking Seminars. 2010. Disponível em: <http://www.escalate.ac.uk/exchange/peerrevie>. Acesso em:

OLIVEIRA, S. R. N. de; SILVA, R. O Lúdico e suas Múltiplas Derivações na Realidade da Educação Infantil. Revista de Divulgação Técnico-Científica do ICPG, v. 3, n. 10, p. 45-46, Jan./Jun. 2008. 